\title{
Complete Cervico-Uretral Transections: A Vesicovaginal Fistula Not Like the Other
}

\author{
Dramane Cisse ${ }^{1 *}$, Abdoulaye Traore ${ }^{2}$, Honoré Jean Gabriel Berthe ${ }^{2}$, Mory Kone ${ }^{1}$, \\ Modibo Coulibaly1, Diamilatou Thiam³, Djibril Traoré1, Bréhima Traoré1, \\ Mamadou Tidiani Coulibaly², Alkadri Diarra², Amadou Kassogue ${ }^{3}$, \\ Moussa Salifou Diallo3, Oumar Guindo ${ }^{3}$
}

\author{
${ }^{1}$ Hôpital Sominé DOLO de Mopti, Mopti, Mali \\ ${ }^{2}$ Université des Sciences des Techniques et des Technologies de Bamako (USTTB), Bamako, Mali \\ ${ }^{3}$ Direction Régionale de la Santé de Mopti, Mopti, Mali \\ Email: *djennecisse@yahoo.fr, ngoaabdoulaye@yahoo.fr, berthonore@hotmail.com \\ konemory@gmail.com,modibocoulibaly@yahoo.com,dralkadri@yahoo.fr, \\ mamadoutc@yahoo.fr,mousalifon@gmail.com,barugdo@yahoo.fr
}

How to cite this paper: Cisse, D., Traore, A., Berthe, H.J.G., Kone, M., Coulibaly, M., Thiam, D., Traoré, D., Traoré, B., Coulibaly, M.T., Diarra, A., Kassogue, A., Diallo, M.S. and Guindo, O. (2021) Complete Cervico-Uretral Transections: A Vesicovaginal Fistula Not Like the Other. Open Journal of Urology, 11, 73-86.

https://doi.org/10.4236/oju.2021.113008

Received: January 13, 2021

Accepted: March 14, 2021

Published: March 17, 2021

Copyright $\odot 2021$ by author(s) and Scientific Research Publishing Inc. This work is licensed under the Creative Commons Attribution International License (CC BY 4.0).

http://creativecommons.org/licenses/by/4.0/

\begin{abstract}
Introduction: Complete cervico-urethral transection is a vesicovaginal fistula characterized by total disinsertion of the urethra from the bladder. It is a fistula of the cervico-urethral intersection threatening the mechanism of continence. The aim of this study was to describe the epidemiological and therapeutic aspects of this type of fistula. Patients and Methods: This was a descriptive retrospective study on patients who have had surgery for cervico-urethral transection from June 01, 2012 to June 01, 2015. Results: Cervico-urethral transections $(\mathrm{n}=76)$ accounted for $33.77 \%$ of all urogenital fistulas admitted to our department of surgery during the study period. The average age was $25.02 \pm 8,6$ years. Married patients accounted for $85.58 \%, 72.36 \%$ had not received any classical education. Fistulas less than one year old made up $56.58 \%$ of cases, associated lesions were perineal tears $25.0 \%$, vaginal sclerosis, $21.05 \%$, vaginal straps, $13.15 \%$, rectovaginal fistula, $2.63 \%$ and the shortness of the urethra less than $2.5 \mathrm{~cm}$ in $42.10 \%$ of cases. All surgeries were performed vaginally with a $98.68 \%$ fistula closure rate and an average of 1.68 surgeries per patient. After closure of the fistula, $10.67 \%$ of patients presented a residual urinary incontinence. Conclusion: Complete cervico-urethral transection is a frequent vesicovaginal fistula. She sometimes exposes to urinary incontinence after closing the fistula. The results of his surgery are often good at the cost of multiple intervention.
\end{abstract}

\section{Keywords}

Vesicovaginal Fistula, Cervico-Urethral Transection, Urinary Incontinence, 
Urethra, Bladder

\section{Background}

Vesicovaginal fistula is an abnormal communication between the bladder and the vagina. It is an ancient pathology known since antiquity. In the Ebers papyrus, 2000BC, it is written "if a woman has urine constantly flowing, she will lose it all her life"; in addition, a vesicovaginal fistula and a perineal tear were found on the mummy of Henhenit dated 2050BC [1] [2]. It usually occurs after difficult and prolonged labor [3]. Once ubiquitous pathology, it has seen its incidence reduced to almost disappear in developed countries due to industrialization, the rise in living standards and progress in monitoring pregnancies and childbirth. However, it remains a public health problem in developing countries due to the weakness of the health system [4] [5] which must be added the low standard of living, illiteracy and harmful practices for women's health such as early marriages, early pregnancies and female genitalia mutilation. The prevalence of vesicovaginal fistula is not known, the WHO estimates that between 2 to 3 million women live with the fistula, the majority of which are in Africa [5] [6] and that the pathology has an annual incidence from 50,000 to 100,000 patients [6].

Several classifications of the pathology have been proposed without real consensus; however the majority of authors agree on the anatomical description of the lesions. Described as a severe vesicovaginal fistula by some authors [7] and complex by others [8] [9] [10], complete cervico-urethral transection is a total disinsertion of the urethra from the bladder. Its real particularity is linked to the fact that it concerns the urethro-cervical crossroads where the striated sphincters involved in the mechanism of voluntary continence, well individualized in the anatomical charts, are not apparent during the surgery. The destruction of the upper lip of the cervix sometimes goes so far back into the pelvis. In this case a dual approach, first, vaginal and pelvic, is necessary to reconstitute the neo-cervix to be anastomosed with the urethra. Sometimes the urethra amputated by the pathological process, even anastomosis to a cervix, does not allow continence because of its brevity. According to these difficulties, it is difficult to predict the outcome of the surgery.

The reestablishment of ureterovesical continuity associated with perfect continence is the expected result. Closure of the fistula, but accompanied by urinary incontinence of different severity, is qualified as a partial outcome to be improved by iterative interventions. This partial result is sometimes difficult to admit, especially in cases where urinary incontinence is total because the symptoms before and after the surgery remain the same. There may sometimes be residual lateralized fistulas in contact with the ischio-pubic and sub-symphyseal branches of difficult treatment. The objective of this study was to describe the epidemiological and therapeutic aspects of these fistulas in the surgical depart- 
ment of the regional hospital called HôpitalSominé DOLO deMopti, Mali.

\section{Patients and Methods}

This was a descriptive retrospective study of patients who have had surgery for cervico-urethral transection between June 01, 2012 and June 01, 2015. Were included any patient operated on for vesico-vaginal fistula during the study period whose intraoperative diagnosis was a complete cervico-urethral transection. Vesico-vaginal fistulas with total destruction of the urethra which are part of another type and for which the treatment is different were not retained by our study. The patients were operated on in routine surgery and in mini campaign which drained a large crowd. The diagnoses were set during outpatient medical consultation and confirmed in the operating room under anesthesia. All of the surgeries were performed vaginally.

For the surgical technique, two situations were present:

A cervico-urethral transection with minimal cervical opening, it was about:

- release after incision of the vaginal mucosa, all around the neck of the bladder by low route;

- perform minimal dissection of the proximal urethra;

- perform a cervico-urethral anastomosis around a Foley CH 16 catheter at six threading points in total in $3 / 0$ polyglycolic acid;

check the tightness of the suture with a methylene blue test before inflating the balloon of the Foley catheter with $5 \mathrm{ml}$ of physiological saline solution; - perform the suture of the vaginal plane. The different times are illustrated in Figure 1.

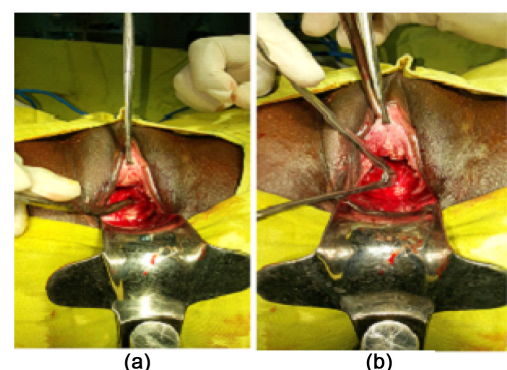

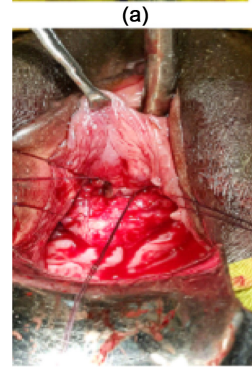

(c)

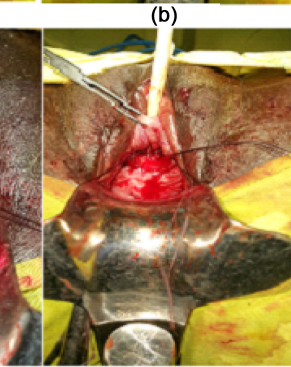

(d)

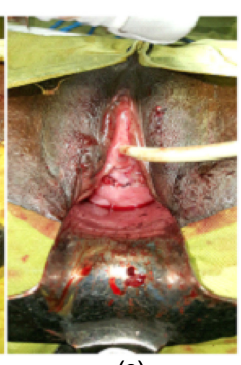

(e)

Figure 1. Cervico-urethral transection with minimal cervical opening. (a) Cervical release; (b) Urethral dissection; (c) Cervico-urethral anastomosis of the upper lip; (d) Cervico-urethral anastomosis of the lower lip; (e) Vaginal closure. 
A large transection with sometimes prolapse of the bladder mucosa, we proceeded by:

- Find and probe the ureters, the ureteral meatus often located on the edges of the fistula, sometimes after good hydration or an intravenous injection of 20 $\mathrm{mg}$ of furosemide;

- Incision and dissection of the entire circumference of the bladder, the delicate parts being located near the uterine neck and in the sub-symphyseal region where the upper lip of the bladder can rise very high in the pelvis;

- Remodeling of the bladder with preparation of a neocervix;

- Minimal dissection of the proximal urethra;

- End-to-end cervico-urethral anastomosis with 6 points in total of 3/0 polygycolic acid thread around a Ch 16 Foley catherter;

- Check the tightness of the suture by a test with methylene blue before inflating the balloon of the Foley catheter with $5 \mathrm{ml}$ of physiological serum;

- Suture the vaginal plane. The different steps are illustrated in Figure 2.

Early mobilization, daily vaginal toileting and daily oral hydration constituted the essential cares during postoperative time. The urethrovaginal catheters were removed 21 days after surgery. A survey sheet was drawn up and included the following data: age, marital status, level of education, concept of excision, circumstances of occurrence, mode of delivery, characteristic of fistula, age of fistula, associated lesions, surgical treatment, treatment results. The expected results were:
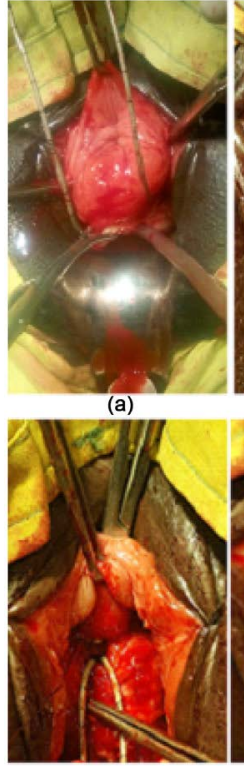

(d)

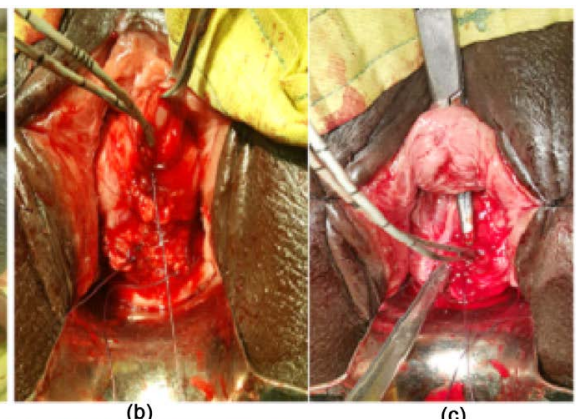

(c)

Figure 2. Large transection with prolapse of the bladder mucosa. (a) Catheterization of the ureters and dissection of the edges of the bladder; (b) Bladder suture with preparation of a neo-bladder neck; (c) Urethral exposure; (d) Cervico-urethral anastomosis of the upper lip; (e) Cervico-urethral anastomosis of the lower lip. 
- Healing, the fistula is closed and continence is total;

- Improvement, the fistula is closed but there is persistent urine leakage through the urethral meatus;

- Treatment failure, there is still a fistula after surgery.

The data collected was analyzed using the epi Info 2005 software version 3.3.2.

\section{Results}

\subsection{Epidemiological Aspects}

Urogenital fistulas $(\mathrm{n}=225)$ accounted for $4.73 \%$ of surgical interventions $(\mathrm{n}=$ 4752). Complete cervico-urethral transections $(n=76)$ accounted for $33.77 \%$ of these urogenital fistulas which were our study subjects. The mean age of the patients was $25.02 \pm 8,6$ years with ranges of 14 years and 65 years. Patients under the age of 18 accounted for $19.74 \%(n=15)$. Patients from the area covered by our hospital accounted for $59.21 \%(n=45)$ of our subjects. Patients married and living with their husbands accounted for $81.58 \%(n=62)$. The level of education was primary in $25 \%(n=19)$ of patients. Type II excision was performed in $48.68 \%$ ( $n=37$ ) of patients. The minimum duration of postoperative follow-up was eight months. The socio-demographic data are highlighted in Table 1.

Table 1. Sociodemographic data of our subjects.

\begin{tabular}{|c|c|c|c|}
\hline Variable & & Frequency & $\%$ \\
\hline \multirow{4}{*}{ Age groups } & under 18 years & 15 & 19.74 \\
\hline & $18-41$ years & 53 & 69.74 \\
\hline & $42-65$ years & 8 & 10,52 \\
\hline & Total & 76 & 100 \\
\hline \multirow{5}{*}{ Origins } & Mopti region & 45 & 59.21 \\
\hline & Other regions & 26 & 34.21 \\
\hline & Ivory Coast & 4 & 5.26 \\
\hline & Burkina Faso & 1 & 1.32 \\
\hline & Total & 76 & 100 \\
\hline \multirow{5}{*}{ Marital status } & Married & 62 & 81.58 \\
\hline & Single & 7 & 9.21 \\
\hline & Divorced & 4 & 5.26 \\
\hline & Widow & 3 & 3.95 \\
\hline & Total & 76 & 100 \\
\hline \multirow{6}{*}{ Educational level } & Koranic & 38 & 50.00 \\
\hline & primary & 19 & 25.00 \\
\hline & secondary & 1 & 1.32 \\
\hline & literacy & 1 & 1.32 \\
\hline & None & 17 & 22.36 \\
\hline & Total & 76 & 100 \\
\hline \multirow{3}{*}{ Excision } & Noexcision & 39 & 51.32 \\
\hline & Type 2 & 37 & 48.68 \\
\hline & Total & 76 & 100 \\
\hline
\end{tabular}


The fistula was obstetric in $98.68 \%(\mathrm{n}=75)$ of the cases and traumatic in $1.32 \%(n=1)$ of the cases. During pregnancy, $64.31 \%(n=46)$ of patients had no prenatal visits. About $62.67 \%(n=47)$ of the patients had given birth at home with a labor duration greater than or equal to 3 days in $60 \%(n=45)$ of the cases. The risk factors for fistulas are summarized in Table 2.

\subsection{Therapeutic Aspects}

\subsubsection{Characteristics of Fistula}

Young fistulas, less than one year old, constituted more than half of the cases,

Table 2. Risk factors for fistulas among our subjects.

\begin{tabular}{|c|c|c|c|}
\hline Variable & & Frequency & $\%$ \\
\hline \multirow{3}{*}{ Etiology } & Obstetrical fistula & 75 & 98.68 \\
\hline & Traumatic fistula & 01 & 1.32 \\
\hline & Total & 76 & 100 \\
\hline \multirow{5}{*}{ Prenatal visit } & No visit & 46 & 61.34 \\
\hline & One visit & 11 & 14.66 \\
\hline & Two visits & 11 & $14 . .66$ \\
\hline & Tree visits & 7 & 9.34 \\
\hline & Total & 75 & 100 \\
\hline \multirow{3}{*}{ Delivery } & At home & 47 & 62.67 \\
\hline & Assisted & 28 & 37.33 \\
\hline & Total & 75 & 100 \\
\hline \multirow{4}{*}{ Labor time } & 0 - 2 days & 30 & 40.00 \\
\hline & 3 days & 32 & 42.67 \\
\hline & More than 3 days & 13 & 17.33 \\
\hline & Total & 75 & 100 \\
\hline \multirow{5}{*}{ Obstetric maneuver } & Abdominal expression & 26 & 34.67 \\
\hline & Forceps & 21 & 28.00 \\
\hline & Others & 4 & 05.33 \\
\hline & None & 24 & 32.00 \\
\hline & Total & 75 & 100 \\
\hline \multirow{3}{*}{ Delivery route } & Vaginal birth & 58 & 77.33 \\
\hline & Caesarean & 17 & 22.67 \\
\hline & Total & 75 & 100 \\
\hline \multirow{4}{*}{ Parity } & Primiparous & 43 & 57.34 \\
\hline & $2-5$ delivery & 22 & 29.33 \\
\hline & 6 and over & 10 & 13.33 \\
\hline & Total & 75 & 100 \\
\hline \multirow{3}{*}{ Newborn condition } & Dead born & 71 & 94.67 \\
\hline & Living & 4 & 5.33 \\
\hline & Total & 75 & 100 \\
\hline
\end{tabular}


$56.58 \%(\mathrm{n}=43)$. Type III perineal tears and vaginal sclerosis were the most frequent associated lesions with $22.37 \%(\mathrm{n}=17)$ and $21.05 \%(\mathrm{n}=16)$ respectively. The urethra was short, less than $2.5 \mathrm{~cm}$ in $42.10 \%(\mathrm{n}=32)$ of cases. It was one-eyed, closed at its proximal end near the bladder neck in 52.63\% $(n=40)$ of cases. The fistula was very large in $35.53 \%$ of the cases. The characteristics of the fistula in our study are presented in Table 3.

\subsubsection{Surgical Aspects}

The patients were operated on under spinal anesthesia in $88.16 \%(n=67)$ of cases and under general anesthesia in $11.84 \%(\mathrm{n}=9)$ of cases. The fistula was closed on the first attempt in $48.69 \%(\mathrm{n}=37)$ of the cases, on the second attempt in $38.16 \%(\mathrm{n}=29)$ of the cases. Urinary incontinence was observed in $10.67 \%(\mathrm{n}=$ 8) of cases after fistula closure. It was observed in 5 patients with a short urethra less than $2.5 \mathrm{~cm}$. Urethral lengthening by vaginal urethroplasty achieved total continence in 4 patients and partial urinary leakage in one patient when she kept urine for a long time. The other three patients had normal urethra and a very large fistula requiring bladder neck remodeling. They benefited from a colpo-suspension using the BURCH technique and continence upon removal of the

Table 3. Characteristics of fistula in our study.

\begin{tabular}{|c|c|c|c|}
\hline Variable & & Frequency & $\%$ \\
\hline & Under one year & 43 & 56.58 \\
\hline & 1 - 3 years & 16 & 21.05 \\
\hline \multirow[t]{6}{*}{ Age of fistula } & $4-6$ years & 5 & 6.58 \\
\hline & $7-10$ years & 12 & 15.79 \\
\hline & Total & 76 & 100 \\
\hline & Perineal tear III & 17 & 22.37 \\
\hline & Vaginal Sclerosis & 16 & 21.06 \\
\hline & Vaginale strap & 10 & 13.15 \\
\hline \multirow[t]{5}{*}{ Associated lesions } & Perineal tear II & 2 & 2,63 \\
\hline & ${ }^{\star} \mathrm{RVF}$ & 2 & 2.63 \\
\hline & None & 29 & 38.16 \\
\hline & Total & 76 & 100 \\
\hline & Short urethra $<2.5 \mathrm{~cm}$ & 32 & 42.10 \\
\hline \multirow[t]{3}{*}{ Urethral length } & Urethra $\geq 2.5 \mathrm{~cm}$ & 44 & 57.90 \\
\hline & Total & 76 & 100 \\
\hline & Permeable urethra & 36 & 47.37 \\
\hline \multirow[t]{3}{*}{ Permeability urethra } & Blind urethra & 40 & 52.63 \\
\hline & Total & 76 & 100 \\
\hline & Minimal cervical orifice & 49 & 64.47 \\
\hline \multirow[t]{2}{*}{ Fistula size } & Very wide cervical orifice & 27 & 35.53 \\
\hline & Total & 76 & 100 \\
\hline
\end{tabular}

${ }^{*}$ RVF: Recto vaginal fistula. 
probe one day after the surgery was effective. The surgical aspects data of our subjects are highlighted in Table 4.

\section{Discussion}

The Regional Hospital of Mopti called Hôpital Sominé DOLO of Mopti is closely linked to the history of vesico-vaginal fistula treatment in Mali. Indeed, since the creation of the "vesico-vaginal fistulas mission in Mali" within the framework of "Médecins du Monde" in 1993 by JA ROBEIN in collaboration with K. OUATTARA [7], several illustrious surgeons including K. OUATTARA, CAMEY M., MONSEUR J. and COLAS JM worked within this framework One of the objectives of this collaboration was to set up a local team with the technical ability to take care of the fistula patients. This dynamic has since been maintained, with the old ones initiating the new ones leading to a permanent team for the management of vesico-vaginal fistulas in routine surgery. The difficulties in assessing the results due to multiple classifications and the problems we faced with these anatomical types of fistulas led us to individualize them. Cervico-urethral transections are severe fistulas classified by CAMEY M [7], complex fistulas of BENCHEKROUN [8] [9] and GUEYE [10], Type IIAb fistulas of WAALDIJK [11] and OAUATTARA K. [12] and in part the group II fistulas of FALANDRY [13].

They made up $33.77 \%$ of our fistula cases. They constituted $22.6 \%$ of the series of DEMISEW et al. [14] in Ethiopia, 37\% of MUSA et al. [15] in Uganda and $66 \%$ of the series by DIALLO et al. [16] in Guinea also including partial transections.

Table 4. Data of chirurgical aspects of our subject.

\begin{tabular}{|c|c|c|c|}
\hline Variable & & Frequency & $\%$ \\
\hline \multirow{3}{*}{ Type of anesthesia } & Spinal anesthesia & 67 & 88.16 \\
\hline & General anesthesia & 9 & 11.84 \\
\hline & Total & 76 & 100 \\
\hline \multirow{2}{*}{ Chirurgical approach } & Vaginal route & 76 & 100 \\
\hline & Total & 76 & 100 \\
\hline \multirow{6}{*}{ Closure of the fistula } & $1^{\text {st }}$ attempt & 37 & 48.69 \\
\hline & $2^{\text {sd }}$ attempt & 29 & 38.16 \\
\hline & $3^{\text {rd }}$ attempt & 6 & 7.90 \\
\hline & $4^{\text {th }}$ attempt & 3 & 3.94 \\
\hline & Fail to close & 1 & 1.31 \\
\hline & Total & 76 & 100 \\
\hline \multirow{3}{*}{ Postoperative continence } & Effective continence & 67 & 89.33 \\
\hline & Urinary incontinence & 8 & 10.67 \\
\hline & Total & 75 & 100 \\
\hline \multirow{3}{*}{ Incontinence surgery } & Vaginal urethroplasty & 5 & 62.5 \\
\hline & BURCH & 3 & 37.5 \\
\hline & Total & 8 & 100 \\
\hline
\end{tabular}


The mean age of our patients was 25.02 years and varied from 14 to 65 years. This mean age was close to the mean age of all types of fistula $(n=225)$, which was 24.73 years. The average age of our series is comparable to that obtained by DEMISEW et al. [14] in Ethiopia, MUSA et al. [15] Uganda and DIALLO et al. [16] in Guinea who reported 25 years, 24 years 25 years respectively. However, it remains lower than those obtained by MOUDOUNI et al. [17] in Morocco and TEKLE et al. [18] in Rwanda who reported 33 years and 34.6 years respectively. Patients under 18 constituted 19.74\% ( $n=15)$ of patients. All had an obstetric cause. This testifies to one of the causes of obstetric fistulas, namely early marriages and early pregnancies. In rural areas, certain marriages take place as soon as the girl sees her period and legally in our country, marriage is authorized from the age of 15 with the consent of the girl's parents. The majority of our patients, $59.21 \%$ were from the area covered by the hospital and $34.21 \%$ from the surrounding areas. The proportion of married patients in our series was $81.58 \%$ almost twice high than the proportion reported by DIALLO et al., 44.4\%. [16]. This high rate of women remaining married despite the disability is believed to be due to the combined action of NGO partners carrying out awareness-raising trips and producing local radio spots accessible to the entire area. These actions have contributed to a greater understanding of the disease despite the low level of education of our patients. Indeed, $73.69 \%$ did not receive any formal education, $25 \%$ a primary level and only $1.32 \%$ a secondary level, on the other hand $75 \%$ had received a Koranic education. The image of the rejected patient living away from the village has become exceptional. The efforts made for social reintegration and especially the creation of income-generating activities have become rare with the patient still living in the family unit.

Cervico-urethral transection was of obstetric origin in $98.68 \%$ of cases. For MOUDOUNI et al. [17] the obstetric cause was found among $88.59 \%$ of patient and among $70 \%$ of patients for TEKLE et al. [18] in Rwanda. In sub-Saharan Africa, the vast majority of vesicovaginal fistulas are of obstetric origin and their prevalence has been estimated at 1.0 and 1.6 per thousand of women of reproductive age [19]. In one case, the fistula was of traumatic origin following the traditional incisional removal of a lithiasis embedded in the cervico-urethral level, which resulted in acute retention of urine. D'ELIA et al. [20] reported a case of a large urethro-vesicovaginal fistula following the surgical removal of a foreign body involuntarily introduced into the bladder. ICHIHARA et al. [21] in Japan also reported a case of cervico-urethral transection following pelvic fracture. The cervico-urethral area is difficult to access in pelvic surgery, iatrogenic etiologies by cesarean and hysterectomy are therefore rare. Primiparous constituted $57.34 \%$ and large multiparous $13.33 \%$ of our patients. DIALLO et al. [16] in Guinea, GUEYE et al. [10] in Senegal and DEMISEW et al. [14] in Ethiopia reported $40.4 \%, 46.0 \%$ and $39.3 \%$ of primiparous respectively. TEKLE et al. [18] in Rwanda reported $22.1 \%$ of primiparous. Beyond the primiparity, all events occurring during the pregnancy monitoring and delivery constitute the predominant risk factors. Indeed, $61.34 \%$ of our patients did not follow any prenatal 
visit and $62.67 \%$ gave birth at home. Regarding assisted deliveries, 37.33\%, none of them started in a center with sufficient technical facilities. Labor began in the village with the help of a traditional birth attendant, before they join in first time a health center without a surgical facility and finally ending in a referral center. This long circuit of the parturient associated with geographical obstacles, insufficient road infrastructure and the dysfunction of the referral-evacuation system partly explain the duration of labor of delivery greater than or equal to three days in $59.7 \%$ of cases. Abdominal expression, an unconventional obstetric maneuver, was used in $34.67 \%$ of patients and forceps delivery in $28.0 \%$ of parturients. The birth was carried out vaginally in $77.33 \%$ of parturients and by caesarean in $22.67 \%$. Newborns resulting from these deliveries were lifeless in $94.67 \%$ of cases. This trend is found in the series by DIALLO et al. [16] in Guinea with a home birth rate of $37.3 \%$ and labor duration greater than or equal to three days in $74.2 \%$ of cases. DEMISEW et al. [14] in Ethiopia also reported a labor time greater than or equal to 2 days in $79.2 \%$ of cases and $85.7 \%$ of stillbirths. Excision, sometimes causing a resistant perineum interfering with the release of the presentation, could prolong the period of expulsion and thus constitute a risk factor. This dystocia is prevented by an episiotomy during the expulsion period in the case the delivery takes place in a health structure with qualified personnel. The proportions of patients excised or not were $48.68 \%$ and $51.32 \%$ respectively in our study, would rather imply the conditions of delivery in the occurrence of vesicovaginal fistula.

The mean duration of fistula at the time of treatment was 4.46 years, fistulas less than 1 year made up $56.58 \%$ of cases and $77.63 \%$ were less than 4 years old. A single case of fistula from a neighboring country was 10 years old. Our average duration of fistula is less than that reported by GOH et al. [22] which was 4.8 years old and that of MUSA et al. [15] in Uganda, and DIALLO et al. [16] in Guinea who reported 7.3 and 11 years respectively. We found no association between the duration of the fistula and the environment of the fistula. Some young fistulas were on a sclera vagina with sometimes straps interfering with access to the fistula while other very old fistulas were on a flexible and easily accessible vagina. The regional hospital of Mopti is the second center for the care of vesicovaginal fistulas in Mali after the teaching hospital "Point G", Bamako, Mali due to the number of cases operated on. In fact, from November 1993 to December 2007, 927 women victims of vesicovaginal fistula were treated there [23] and 225 women of all types during our study period. The awareness-raising actions of partner NGOs in the region and free healthcare services, food and accommodation for women victims of fistulas lead them to consult early in the event of urine leakage after childbirth. About $59.21 \%$ of our patients resided in the Mopti region. The vesicovaginal fistula was associated with a perineal tear in $25.0 \%$ of cases, including $22.37 \%$ of type III. These perineal tears, despite the extra time to repair them, allow good exposure of the fistula if they are isolated. Vaginal sclerosis, $21.06 \%$ and vaginal bridles, $13.15 \%$, on the other hand make exposure and dissection difficult and require an additional section of bridle or 
episiotomy. The rectovaginal fistula encountered in two cases $(2.63 \%)$ was successfully repaired during the same procedure. Cervico-urethral transection was associated with a certain degree of urethral destruction, making it short less than $2.5 \mathrm{~cm}$ in $42.10 \%$ of cases. The length of the urethra is an important determinant of continence after fistula closure. The shorter the urethra, the greater the risk of incontinence after the fistula has closed. The large fistulas constituting $35.53 \%$ of cases require a remodeling of the cervix with the constitution of a new cervix, which despite its high fixation behind the pubic symphysis, exposes to urinary incontinence after the closure of the fistula.

Spinal anesthesia was attempted in all patients and was successful in $88.16 \%$ of them. The remainder, $11.84 \%$ received general anesthesia after failure of locoregional anesthesia. Spinal anesthesia allows early mobilization, rapid feeding and less postoperative morbidity associated with reduced anesthesia. It is the type of anesthesia most used for DEMISEW et al. [14] in Ethiopia with $70.8 \%$. The vaginal route approach was used in all patients. MOUDOUNI et al. [17] used the vaginal route in $89 \%$ of cases for BENCHEKROUN type I and II fistulas (urethral and cervico-urethral). Indeed the vaginal route is the best indicated for the fistulas of the cervico-urethral crossroads. However, in certain situations where the upper lip of the cervix is inaccessible and tucked far behind the pubic symphysis, the mixed approach, upper and lower, may be necessary. This vaginal approach allowed us to close 75 of 76 fistulas (98.68\%), with an average of 1.68 surgical operations per patient. This fistula closure rate was $68.1 \%$ for group II fistulas of DUMURGUIER and FALANDRY [13] with one repeatedly in 33\% of cases for group II and III. MOUDOUNI et al. [17] had a 92\% success rate after one to three interventions on average for BENCHEKROUN type II fistulas.

Urinary incontinence after closure of the fistula was observed in $10.67 \%$ of cases. GOH [22] in Ethiopia, out of 987 cases of all types of fistula obtained 24\% urinary incontinence. For BROWNING [24], this urinary incontinence rate can reach $60 \%$ if the fistula reaches the neck or the urethra, which is the case in a complete cervico-urethral transection. For the prevention of this urinary incontinence, ARROSMITH [25] suggests the addition of a nearby pedicled and well vascularized tissue. This technique was chosen by MOUDOUNI et al. [17], DIALLO et al. [16] who used the MARTIUS process. TEBEU et al. [26], on the other hand, found that the observed results of urinary fistula treatment were similar whether or not MARTIUS graft interposition was performed. For our part, we have not made any contribution of neighborhood fabric. The urinary incontinence observed after closure of the fistula was subsequently treated based on the two anatomical requirements of continence mentioned by DUMURGUIER and FALANDRY [13], which are the length of the functional urethra and the angle of cervico-urethral closure. Thus, urinary incontinence with short urethra benefited from urethral lengthening by urethroplasty in vagina and urinary incontinence with normal urethral length benefited from a colpo-suspension via the suprapubic route using the BURCH technique. 
The limits of our study come from the fact that most of the authors treat vesico-vaginal fistulas in general and that the transections are not individualized in particular in the literature. It was difficult to compare our results, we had to go into the classifications of each author to identify this type of fistula. The results of treating these often problematic fistulas are often not individualized. A larger sample would undoubtedly have enabled us to obtain results with a high level of proof. The study looked at the surgical aspect of cervico-urethral transection where the particularity lies in urinary incontinence which can persist after the closure of the fistula and even be complete. A healed cervico-urethral transection has no particularity compared to other healed vesico-vaginal fistulas, a study on the quality of life of cured patients should therefore be of interest to all types of fistulas without distinction.

\section{Conclusion}

Complete cervico-urethral transections are fairly frequent vesicovaginal fistulas. Their treatment is surgical and is mainly done through the vaginal route. Sometimes treatment results are good at the cost of multiple surgery interventions. Residual urinary incontinence can be corrected by lengthening urethroplasty when the shortness of the urethra is the cause or by colposuspension when the urethra is of normal length and the neck angle very open.

\section{Conflicts of Interest}

The authors declare no conflicts of interest regarding the publication of this paper.

\section{References}

[1] Bouffioux, C.H. and de Leval, J. (1987) Expérience comparée des fistules vésico-vaginale en Belgique et en Guinée Conakry. Acta Urologica Belgica, 55, 597-607.

[2] Mahfouz, N. (1957) Urinary Fistulae in Women. BJOG, 64, 23-34. https://doi.org/10.1111/j.1471-0528.1957.tb02595.x

[3] Arrowsmith, S., Hamlin, E.C. and Wall, L.L. (1996) Obstructed Labor Injury Complex: Obstetric Fistula Formation and the Multifaceted Morbidity of Maternal Birth Trauma in the Developing World. Obstetrical \& Gynecological Survey, 51, 568-574. https://doi.org/10.1097/00006254-199609000-00024

[4] Ndiaye, P., AmoulKini, G., Adama, F., Idrissa, A. and Tal-Dia, A. (2009) Urogenital Fistula of Obstetric Origin (Fugo): Cost of Care at the Niamey National Hospital (Niger). Revue dépidémiologie et de Santé Publique, 57, 374-379. https://doi.org/10.1016/j.respe.2009.04.010

[5] Aristide Kabore, F., Kambou, T., Ouattara, A., Zango, B., Yameogo, C., Kirakoya, B., et al. (2014) Epidemiological, Etiological and Psychosocial Aspects of Urogenital Fistula in a Cohort of 170.

[6] WHO (2006) Obstetric Fistula: Guiding Principles for Clinical Management and Programme Development. World Health Organization, Geneva.

[7] Camey, M. (1998) Les fistules obstétricales. Progès en Urologie, Paris, 328.

[8] Benchekroun, A., Lakrissa, A., Essakali, H.N., Faik, M., Abbaka, T., Hachimi, M., 
Marzouk, M. and Benabderrazek, T. (1987) Vesicovaginal Fistulas: About 600 Cases. Journal of Urology (Paris), 93, 151-158.

[9] Benchekroun, A., El Alj, H.A., El Sayegh, H., Lachkar, A., Nouini, Y., et al. (2003) Vesico-Vaginal Fistula: Report of 1050 Cases. Annales d Urologie, 37, 194-198. https://doi.org/10.1016/S0003-4401(03)00053-6

[10] Gueye, S.M., Ba, M., Sylla, C., Diagne, B.A. and Mensah, A. (1992) Vesico-Vaginal Fistulas: Etiopathogenic and Therapeutic Aspects in Senegal. Journal of Urology, 98, 148-151.

[11] Creanga, A.A. and Genadry, R.R. (2007) Obstetric Fistulas: A Clinical Review. International Journal of Gynecology \& Obstetrics, 99, S40-S46.

https://doi.org/10.1016/j.ijgo.2007.06.021

[12] Diakité, M.L., Ouattara, K. and Tembely, A. (2015) Some Thoughts on the Classification of African Obstetric Fistula. Médecine et Santé Tropicales, 25, 146-155. https://doi.org/10.1684/mst.2014.0387

[13] Dumurgier, C. and Falandry, L. (2012) The Surgery of Obstetric Fistulas. Bulletin de L'Académie Nationale de Médecine, 196, 1535-1556.

[14] Demisew, A.S., Ahadu, W.A. and Desta, H.G. (2016) Characteristics and Repair Outcome of Patients with Vesicovaginal Fistula Managed in Jimma University Teaching Hospital, Ethiopia. BMC Urology, 16, 41. https://doi.org/10.1186/s12894-016-0152-8

[15] Musa, K., Ssalongo, W., Kabakyenga, J., Mukiibi, N., Senkungu, J., Stenson, A. and Mukasa, P. (2011) Predictors and Outcome of Surgical Repair of Obstetric Fistula at a Regional Referral Hospital, Mbarara, Western Uganda. BMC Urology, 11, 23. https://doi.org/10.1186/1471-2490-11-23

[16] Diallo, A.B., Sy, T., Baha, M.D., Diallo, T.M.O., Barry, M.S., Baha, I., Barry, T.H., Blanchote, J., Rochat, C.H. and Diallo, M.B. (2016) Obstetric Vesicovaginal Fistulas in Guinée: Analysis of Data from Tree Care Site of the OGN Engender Health. Progrès en Urologie, 26, 145-151. https://doi.org/10.1016/j.purol.2016.01.006

[17] Moudouni, S., Nouri, M., Koutani, A., Attya, A.I., Hachimi, M. and Lakrissa, A. (2001) Obstetric Vesicovaginal Fistulas. About 114 Cases. Progrès en Urologie, 11, 103-108.

[18] Egziabher, T.G., Ngoga, E., Karenzi, B. and Kateera, F. (2015) Obstetric Fistula Management and Predictors of Successful Closure among Women Attending a Public Tertiary Hospital in Rwanda: A Retrospective Review of Records. BMC Research Notes, 8, 774. https://doi.org/10.1186/s13104-015-1771-y

[19] Maheu-Giroux, M., et al. (2015) Prevalence of Symptoms of Vaginal Fistula in 19 Sub-Saharan Africa Countries: A Meta-Analysis of National Household Survey Data. The Lancet Global Health, 3, e271-e278. https://doi.org/10.1016/S2214-109X(14)70348-1

[20] D’Elia, C., Curti, P., Cerruto, M.A., Monaco, C. and Artibani, W. (2015) Large Urethro-Vesico-Vaginal Fistula Due to a Vaginal Foreign Body in a 22-Year-Old Woman: Case Report and Literature Review. Urologia Internationalis, 95, 120-124. https://doi.org/10.1159/000365421

[21] Ichihara, K., Masumori, N., Takahashi, S., Miyao, N. and Kato, R. (2015) Bladder Neck Rupture and Vesicovaginal Fistula Associated with Pelvic Fracture in Female. Lower Urinary Tract Symptoms, 7, 115-117. https://doi.org/10.1111/luts.12056

[22] Goh, T.W.J., Browning, A. and Chang, A. (2008) Predicting the Risk of Failure of Closure of Obstetric Fistula and Residual Urinary Incontinence Using a Classification System. International Urogynecology Journal, 19, 1659-1662. 
https://doi.org/10.1007/s00192-008-0693-9

[23] Ministère de la Santé du Mali (2009) Stratégie Nationale de Prévention et de prise en charge de la fistule obstétricale. "Zéro cas de fistule obstétricale". Bamako, Janvier 2009, 30 p.

[24] Browning, A. (2004) Prevention of Residual Urinary Incontinence Following Successful Repair of Obstetric Vesicovaginal Fistula Using Fibro Muscular Sling. BJOG, 111, 357-361. https://doi.org/10.1111/j.1471-0528.2004.00080.x

[25] Arrowsmith, S.D. (1994) Genitourinary Reconstruction in Obstetric Fistulas. Journal of Urology, 152, 403-406. https://doi.org/10.1016/S0022-5347(17)32749-0

[26] Tebeu, P.M., Fokom-Domgue, J., KengneFosso, G., TjekBiyaga, P., Nelson Fomulu, J. and Rochat, C.H. (2015) Comparative Study of the Result of the Cure of Vesicovaginal Fistulas with and without Interposition of the Flap of Martius: A Cameroonian Experience. Progrès en Urologie, 25, 1225-1231.

https://doi.org/10.1016/j.purol.2015.07.005 